\title{
Pendekatan Baru untuk Merepresentasi Informasi di Bidang Pendidikan Menggunakan Kombinasi Ontologi
}

\author{
Selvia Ferdiana Kusuma ${ }^{\# 1}$, Fadelis Sukya ${ }^{\# 2}$, Agustono Heriadi ${ }^{\# 3}$ \\ \#Program Studi Manajemen Informatika, Politeknik Negeri Malang PSDKU Kediri \\ Jl. Lingkar Maskumambang No.1, Sukorame, Kec. Mojoroto, Kota Kediri, Jawa Timur 64119 \\ ${ }^{1}$ selvia.ferdianalpolinema.ac.id \\ zfadelis.sukya@polinema.ac.id \\ 3agustono.heriadiepolinema.ac.id
}

\begin{abstract}
Abstrak - Ontologi adalah sebuah konsep yang dirancang untuk merepresentasikan relasi antar informasi. Ontologi dapat digunakan untuk merepresentasikan informasi berbentuk hierarki maupun non hierarki. Namun, model ontologi yang ada saat ini pada umumnya selalu bersifat domain spesifik. Peran ahli sangat dominan ketika membuat ontologi yang bersifat domain spesifik. Kelengkapan informasi pada ontologi tergantung pada kemampuan ahli pada domain tersebut dan ahli di bidang teknologi informasi untuk merepresentasikan informasi ke dalam bentuk ontologi. Oleh sebab itu diperlukan model ontologi baru agar dapat menghasilkan ontologi yang tidak bersifat domain spesifik. Sehingga mempermudah proses representasi informasi ke dalam bentuk ontologi dan mengurangi peran ahli dalam proses pembuatan ontologi tersebut. Model ontologi baru yang diusulkan adalah kombinasi dari ontologi taksonomi dan ontologi kalimat. Informasi berbentuk hierarki akan direpresentasikan dalam bentuk ontologi taksonomi, sedangkan informasi nonhierarki akan direpresentasikan dalam bentuk ontologi kalimat. Berdasarkan uji coba yang telah dilakukan, diketahui bahwa kombinasi ontologi yang diusulkan dapat menghasilkan ontologi yang tidak bersifat domain spesifik, mempermudah proses pembangkitan ontologi, dan mengurangi peran ahli dalam pembuatan ontologi tersebut.
\end{abstract}

Kata kunci - Representasi informasi, ontologi, buku teks, kombinasi ontologi

\section{Pendahuluan}

Representasi informasi di dunia pendidikan erat kaitannya dengan mind map dan concept map. Mind map adalah representasi informasi yang berbentuk gambar maupun tulisan dengan berbagai warna [1]. Mind map tidak memiliki aturan yang baku, oleh sebab itu kelengkapan informasi maupun cara merepresentasikan informasi tersebut sangat tergantung dari kreativitas dan pemahaman dari pembuatnya. Sedangkan concept map adalah representasi informasi dalam bentuk hierarki dan bersifat lebih formal, jika dibandingkan dengan mind map
[2]. Concept map berfokus pada struktur / hierarki informasi, sehingga tidak semua informasi dapat disimpan dalam bentuk ini. Mind map dan concept map dapat berpengaruh terhadap peningkatan pemahaman siswa [3][4]. Namun kedua jenis representasi informasi ini belum dapat benar-benar menyimpan informasi yang ada secara keseluruhan. Mind map tidak memiliki aturan penyimpanan informasi yang baku sehingga informasi yang sama dapat direpresentasikan dalam bentuk yang berbeda-beda oleh setiap orang. Sementara concept map memiliki aturan yang lebih baku namun hanya menyimpan informasi dalam bentuk hierarki. Padahal informasi yang lengkap dan saling berelasi sangat diperlukan untuk memperluas dan memperdalam pengetahuan siswa terkait suatu objek pembahasan. Selain itu relasi informasi juga diperlukan sebagai dasar pembuatan soal-soal evaluasi yang bertipe High Order Thinking Skill (HOTS).

Oleh sebab itu penelitian ini memperkenalkan model penyimpanan informasi baru berbasis kombinasi ontologi. Ontologi adalah representasi informasi dalam bentuk graph yang saling berelasi [5]. Ontologi berfungsi untuk merelasikan ratusan bahkan ribuan informasi. Ontologi memiliki aturan yang baku dalam proses penyimpanan informasi. Pendekatan baru dalam merepresentasikan informasi di bidang pendidikan dalam bentuk ontologi ini dapat membantu guru, maupun siswa untuk mendapatkan informasi yang lebih detail dari sebuah objek. Saat ini ontologi sudah banyak digunakan untuk menyimpan informasi di berbagai bidang misalkan cyber security [6], kesehatan [7], pendidikan [8] dan lain sebagainya. Penelitian-penelitian terkait penggunaan ontologi pada bidang pendidikan diantaranya adalah penggunaan ontologi untuk identifikasi kemampuan siswa sebagai penunjang proses adaptive learning system (ALS) [9], penggunaan ontologi untuk sistem tanya jawab [10], penggunaan ontologi untuk mendesain sistem pendidikan [11], penggunaan ontologi untuk membentuk relasi 
informasi dari sebuah materi pembelajaran [12], dan penggunaan ontologi untuk membangkitkan pertanyaan [13][14].

Ontologi memiliki empat komponen utama untuk merepresentasikan informasi dari sebuah domain. Komponen tersebut terdiri dari konsep(class) yang mewakili sekumpulan entitas dalam suatu domain, relasi(object property) digunakan untuk menentukan interaksi antar konsep, entitas (instance) merupakan sekumpulan objek pada suatu domain, dan properti(data property) merupakan atribut yang dimiliki oleh entitas [15]. Model ontologi yang ada pada umumnya selalu bersifat spesifik pada domain tertentu karena relasi yang digunakan menyesuaikan dengan domain tersebut [16][17]. Peran ahli sangat dominan ketika membuat ontologi yang bersifat domain spesifik [18][19][20][21]. Kelengkapan informasi tergantung pada kemampuan ahli pada domain tersebut dan ahli di bidang teknologi informasi untuk merepresentasikan informasi. Contohnya pada penelitian Baeva tentang pembentukan ontologi untuk menyimpan informasi dari mata pelajaran sejarah [12]. Pada penelitian tersebut, perlu adanya banyak penambahan class / relasi baru (object property) untuk dapat merepresentasikan hubungan antar instance. Proses penentuan class maupun object property tersebut bergantung pada kemampuan domain expert untuk merepresentasikan pengetahuannya. Oleh sebab itu diperlukan model ontologi baru agar dapat menghasilkan ontologi yang tidak bersifat domain spesifik, mempermudah proses representasi informasi ke dalam bentuk ontologi dan mengurangi peran ahli dalam proses pembuatan ontologi.

Model ontologi baru yang diusulkan adalah kombinasi dari ontologi taksonomi dan ontologi kalimat. Informasi berbentuk hierarki akan direpresentasikan dalam bentuk ontologi hierarki, sedangkan informasi non-hierarki akan direpresentasikan dalam bentuk ontologi kalimat.

\section{Penelitian Terdahulu}

Beberapa penelitian telah menggunakan ontologi untuk merepresentasikan informasi pada domain yang berbeda beda. Namun proses yang digunakan untuk membentuk ontologi tersebut tetap sama. Peran ahli pada setiap domain diperlukan untuk membantu ontologi engineer merepresentasikan informasi pada domain tersebut.

Penelitian yang dilakukan Baskoro mencoba merepresentasikan pengetahuan pada domain kriminalitas [18]. Pada penelitian tersebut peran ahli diperlukan untuk melakukan penentuan class, object property, data property dan contoh instance dari setiap class. Beberapa penelitian terkait metodologi yang diusulkan untuk membangkitkan ontologi juga masih menggunakan peran ahli yang sangat dominan [19][20][21]. Model ontologi yang memerlukan peran ahli secara dominan untuk memetakan maupun menambahkan pengetahuannya untuk membentuk ontologi pada penelitian ini selanjutnya disebut model ontologi konvensional.
Jika konteks informasi yang ingin disimpan berupa informasi yang telah terstruktur maka penggunaan model ontologi konvensional masih mungkin digunakan. Hal tersebut karena sebenarnya informasi yang akan disimpan sudah terkelompokkan sebelumnya. Misalkan pada domain kesehatan, informasi yang ingin disimpan adalah tentang berbagai jenis penyakit, gejala, penyebab, dan cara penyembuhan. Relasi maupun instance yang diperlukan untuk menghubungkan informasi ini tidak akan meluas karena hanya berkutat pada gejala, penyebab, dan cara penyembuhan dari penyakit [14]. Namun penggunaan model ontologi konvensional ini dianggap tidak sesuai jika digunakan untuk menyimpan informasi berasal dari buku teks dan dalam konteks ini digunakan untuk menyimpan informasi dari materi pelajaran tertentu. Hal tersebut karena informasi yang ada di buku teks biasanya bersifat meluas sehingga dimungkinkan adanya penambahan-penambahan class atau relasi baru diluar domain tersebut, seperti contohnya pada penelitian Baeva [12].

\section{METODE}

Metode representasi informasi menggunakan ontologi pada penelitian ini memiliki 7 tahapan utama yaitu pengumpulan dan analisis dataset, identifikasi jenis kalimat, penyesuaian bentuk kalimat, konversi kalimat ke dalam protégé, pengambilan informasi dari protégé, konversi informasi dari protégé menjadi gabungan kalimat utuh dan terakhir adalah proses evaluasi hasil. Setiap tahapan utama memiliki detail pada masing-masing tahapan. Gambaran metodologi yang diterapkan untuk membangkitkan ontologi di bidang pendidikan ditunjukkan pada Gambar 1. Penjelasan detail dari setiap proses dijelaskan pada sub bab A sampai dengan G.

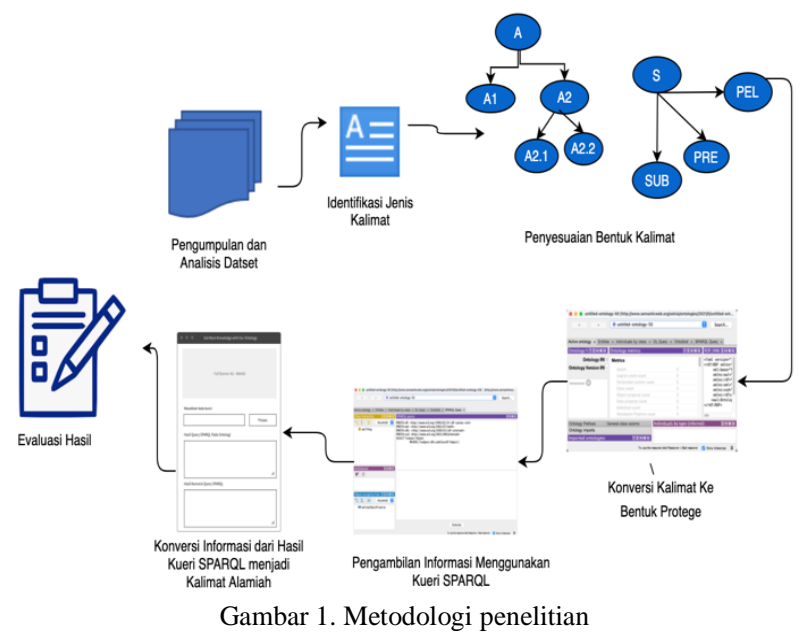

\section{A. Pengumpulan dan Analisis Dataset}

Dataset yang digunakan pada penelitian ini adalah buku teks Ilmu Pengetahuan Alam kelas 4 sekolah dasar dan buku teks Ilmu Pengetahuan Sosial kelas 4 sekolah dasar. Dataset yang digunakan berupa kalimat-kalimat dari masing-masing buku teks. Penelitian ini hanya akan 
menggunakan 1 bab dari masing-masing jenis buku sebagai uji coba. Selain pengumpulan, pada proses ini juga dilakukan analisis terhadap dataset. Analisis meliputi analisis terhadap struktur kalimat dan kompleksitas kalimat dari setiap jenis buku. Kalimat-kalimat kompleks akan disederhanakan. Syarat penyederhanaan kalimat kompleks adalah tidak boleh merubah informasi utama dari kalimat tersebut. Misalnya kalimat "Ada pula karnivora yang bernapas dengan paru-paru. Misalnya katak dan harimau." akan disederhanakan menjadi "Karnivora yang bernapas dengan paru-paru adalah katak dan harimau". Selain itu kalimat yang menggunakan kata ganti juga perlu diubah sesuai dengan objek yang dirujuk, misalkan kalimat "Hewan tersebut memiliki bentuk permukaan gigi geraham yang berlekuk-lekuk tajam" diubah menjadi "Hewan karnivora memiliki bentuk permukaan gigi geraham yang berlekuk-lekuk tajam”.

\section{B. Identifikasi Kalimat}

Identifikasi kalimat bertujuan untuk mengenali jenis kalimat dan jenis kata yang digunakan pada kalimat tersebut. Pada penelitian ini kalimat diklasifikasikan menjadi 2 jenis yaitu kalimat berbentuk hierarki dan kalimat berbentuk non-hierarki. Identifikasi kalimat diperlukan untuk mempermudah penentuan jenis ontologi yang akan digunakan untuk merepresentasikan informasi pada kalimat tersebut. Contoh kalimat yang merepresentasikan informasi berbentuk hierarki adalah "Contoh hewan karnivora adalah buaya, katak, dan kucing. Sedangkan contoh kalimat yang merepresentasikan informasi non-hierarki adalah "Katak bernapas dengan paru-paru". Informasi berbentuk hierarki akan direpresentasikan ke dalam bentuk ontologi taksonomi, sedangkan informasi berbentuk non-hierarki akan direpresentasikan dalam bentuk ontologi kalimat. Proses identifikasi jenis informasi dilakukan berdasarkan keyword yang ada pada suatu kalimat. Kalimat yang merepresentasikan informasi berbentuk hierarki biasanya memiliki kata "adalah", "terdiri dari","meliputi", atau "yaitu" yang disertai dengan beberapa tanda koma dalam satu kalimat. Kalimat yang tidak memiliki keyword tersebut akan diklasifikasikan ke dalam kalimat nonhierarki.

\section{Penyesuaikan Bentuk Kalimat}

Penyesuaian bentuk kalimat dilakukan untuk mempermudah proses konversi informasi pada protégé. Kalimat berbentuk hierarki diubah menjadi seperti ini "Hewan; Karnivora: buaya, katak, kucing". Class/ subclass tertulis di bagian pertama dan kedua, kemudian diikuti instance dari class tersebut. Proses penyesuaian pada kalimat berbentuk hierarki dapat dilakukan dengan menghilangkan jenis kata selain kata benda pada kalimat yang tergolong sebagai kalimat berbentuk hierarki. Kalimat yang tergolong kalimat hierarki biasanya terbentuk dari gabungan kata benda. Kalimat yang tidak terklasifikasi sebagai kalimat berbentuk hierarki maka akan langsung dianggap sebagai kalimat non-hierarki.
Kalimat non-hierarki akan diubah ke dalam bentuk parse tree. Identifikasi susunan kata pada kalimat non-hierarki dilakukan berdasarkan hierarki dari parse tree. Proses awal yang dilakukan adalah menandai setiap jenis kata kemudian merepresentasikan hubungan antar kata berdasarkan hierarki aturan pada parse tree. Flowchart proses pembentukan parse tree ditunjukkan pada Gambar 2.

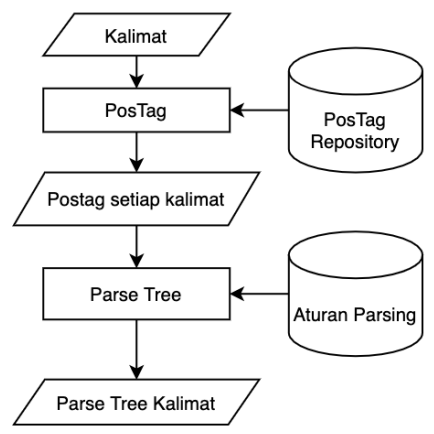

Gambar 2. Flowchart pembentukan parse tree

Studi tentang parsing bahasa Indonesia telah banyak dilakukan [22][23][24][25]. Tata bahasa yang digunakan pada Bahasa Indonesia merujuk pada struktur Subjek, Predikat, Objek, Pelengkap dan Keterangan (SPOPelK). Subjek(S) adalah unsur pokok dalam kalimat biasanya berupa kata benda. Predikat(P) adalah unsur pokok dalam kalimat yang biasanya berupa kata kerja. Objek $(\mathrm{O})$ bersifat wajib dalam kalimat transitif dan dapat menjadi subjek pada kalimat pasif. Pelengkap(Pel) adalah unsur kalimat yang fungsinya seperti objek tetapi yang membedakannya adalah pelengkap tidak bisa diubah menjadi subjek pada kalimat pasif. Pelengkap biasanya terletak setelah predikat atau objek. Keterangan(K) merupakan unsur kalimat yang memberikan informasi mengenai tempat, waktu, cara, sebab dan tujuan. Unsurunsur yang digunakan pada struktur tata bahasa pada Bahasa Indonesia ditunjukkan pada Tabel 1 [26].

TABEL I

UNSUR SPOPEIK DALAM KLAUSA [9]

\begin{tabular}{|c|c|c|}
\hline Unsur & Tagger & Contoh \\
\hline Subjek (SUB) & $\begin{array}{l}\text { PRP, NN, NNP, } \\
\text { Frase Nominal }\end{array}$ & $\begin{array}{l}\text { Saya, hewan, } \\
\text { harimau }\end{array}$ \\
\hline Predikat (PRE) & $\begin{array}{l}\text { VB, JJ, Frase } \\
\text { VERB }\end{array}$ & Memakan, cepat \\
\hline Objek (OBJ) & $\begin{array}{l}\text { NN, NNP, Frase } \\
\text { Nominal }\end{array}$ & Tumbuhan, mawar \\
\hline $\begin{array}{l}\text { Pelengkap } \\
\text { (PEL) }\end{array}$ & $\begin{array}{l}\text { JJ, Frase JJ, Frase } \\
\text { Nominal }\end{array}$ & Cepat, dengan kuat \\
\hline $\begin{array}{l}\text { Keterangan } \\
\text { (KET) }\end{array}$ & Frase Keterangan & $\begin{array}{l}\text { Ketika berusia } 3 \\
\text { bulan }\end{array}$ \\
\hline NNP & $\begin{array}{l}\text { NN NN,NN PR,NN } \\
\text { PRP,NN NN, NN } \\
\text { JJ, NN JJ PR, NND } \\
\text { NN, NN CC }\end{array}$ & Hewan liar \\
\hline $\begin{array}{l}\text { Frase Nominal } \\
\text { (FNOM) }\end{array}$ & $\begin{array}{l}\text { CD, CD NN, CD } \\
\text { CD, CD NND, CD } \\
\text { NND NN, CD }\end{array}$ & Tiga bulan \\
\hline
\end{tabular}




\begin{tabular}{|l|l|l|}
\hline \multicolumn{1}{|c|}{ Unsur } & \multicolumn{1}{c|}{ NNP, FNOM PRP } & \multicolumn{1}{c|}{ Contoh } \\
\hline $\begin{array}{l}\text { Frase Verb } \\
\text { (FVERB) }\end{array}$ & $\begin{array}{l}\text { SC VB, MD VB, } \\
\text { VB VB, MD RB } \\
\text { VB, VB JJ, NN } \\
\text { VB, RB VB }\end{array}$ & Sangat terasa \\
\hline $\begin{array}{l}\text { Frase } \\
\text { Adjective } \\
\text { (FADJ) }\end{array}$ & JJ RB, JJ NN, JJ JJ, & Dengan cepat \\
\hline $\begin{array}{l}\text { Frase Preposisi } \\
\text { (FPREP) }\end{array}$ & $\begin{array}{l}\text { IN FPREP, IN NN, } \\
\text { IN NN PR, IN NNP }\end{array}$ & Di hutan \\
\hline $\begin{array}{l}\text { Frase Preposisi } \\
\begin{array}{l}\text { Pelengkap } \\
\text { (FPREPPel) }\end{array}\end{array}$ & NN NN NN, SC RB & Di kawasan hutan \\
\hline $\begin{array}{l}\text { Kata } \\
\text { penghubung }\end{array}$ & CC, SC, “, & $\begin{array}{l}\text { dan, atau, tetapi, } \\
\text { yang, ketika, } \\
\text { setelah }\end{array}$ \\
\hline
\end{tabular}

Proses parsing memiliki aturan yang telah ditentukan. Aturan parsing ditunjukkan pada Gambar 3. Setiap unsur seperti Subjek, Predikat, Objek, Pelengkap dan Keterangan memiliki aturan yang berbeda beda. Penyusun dari aturan tersebut adalah pos tagging dasar yang terdiri dari VB, NN, PRP, JJ, CC, SC, frasa nominal (FNOM), frasa kata kerja (FVERB), frasa kata sifat(FADJE), frasa preprosisi (FPREP), frasa preprosisi pelengkap (FPREPPel), dan kata penghubung (SC, CC). Proses parsing ini dapat dilakukan dengan library nltk.ChartParser dengan fungsi parse(). Hasil parsing adalah pohon kalimat. Kalimat (S) dapat berupa gabungan dari SUB dan PRE atau SUB, PRE dan OBJ. S dapat dibentuk dari beberapa kemungkinan seperti yang ditunjukkan pada Gambar 3. Satu kalimat juga dapat terbentuk dari gabungan dua kalimat atau lebih yang disatukan oleh kata hubung SC atau CC.

S ->SUB PRE|SUB PRE OBJ JSUB PRE PEL|SUB PRE OBJ PEL|SUB
PRE KET | SUB PRE OBJ KET | SUB PRE PEL KET | SUB PRE OBJ
PEL KET | PRE OBJ KET
S -> S CC S | S SC S
SUB -> FNOM | PRP | NN | NNP
PRE -> VB | JJ | FVERB
OBJ -> NN|FNOM
PEL -> JJ | FNOM | FADJE | FPREPPel | FVERBPel KET -> FPREP
FNOM->CD CD NN $\mid$ CD CD $\mid$ CD NND $\mid$ CD NND NN|FNOM PRP|CD
NNP
NNP -> NN NN | NN PR | NN PRP | NN NN PR | NN NN | NN JJ |
NN JJ PR | NND NN | NN CC NN | NNP CC NNP | NN NNP | NN CC
NNP
FVERB -> SC VB | MD VB | VB VB | MD RB VB | NEG VB | VB JJ |
NN VB | RB VB FVERBPel -> SC VB NN
FADJE -> JJ RB | JJ NN | NN JJ | JJ JJ | JJ VB | NEG JJ | RB JJ | SC JJ
FPREP -> IN FPREP |IN NN | IN NN NN | IN NN IN | IN JJ | IN NN
NNP
FPREPPel -> INP NN NN | SC RB NN

Gambar 3. Aturan parsing pada bahasa indonesia

Contoh hasil penanda (PosTag) jenis kata dari kalimat non-hierarki adalah "Katak(nn) bernapas(vb) dengan(in) paru-paru(nn)". Sedangkan parse tree yang dihasilkan yaitu "Sub(Katak(nn)) Pre(bernapas(vb)) Ket(Fprep (dengan(in)) (paru-paru(nn)))". Proses pembentukan parse tree dilakukan secara otomatis menggunakan library NLTK pada Python.

\section{Konversi Kalimat ke Protégé}

Konversi kalimat ke protégé dilakukan berdasarkan struktur kalimat yang digunakan. Proses konversi dilakukan dengan algoritma khusus yang telah dibuat. Setiap kalimat akan diubah dalam bentuk XML sesuai komponen pada protégé. Pseudocode yang digunakan untuk mengkonversi kalimat berbentuk hierarki dan berbentuk parse tree ke dalam protégé ditunjukkan pada Gambar 4. Masukan kalimat berbentuk hierarki maupun non-hierarki yang digunakan di tunjukkan pada sub bab B. Function yang ada pada Gambar 4 digunakan untuk mengubah masukan berupa kalimat tersebut menjadi rangkaian objek berformat $\mathrm{xml}$.

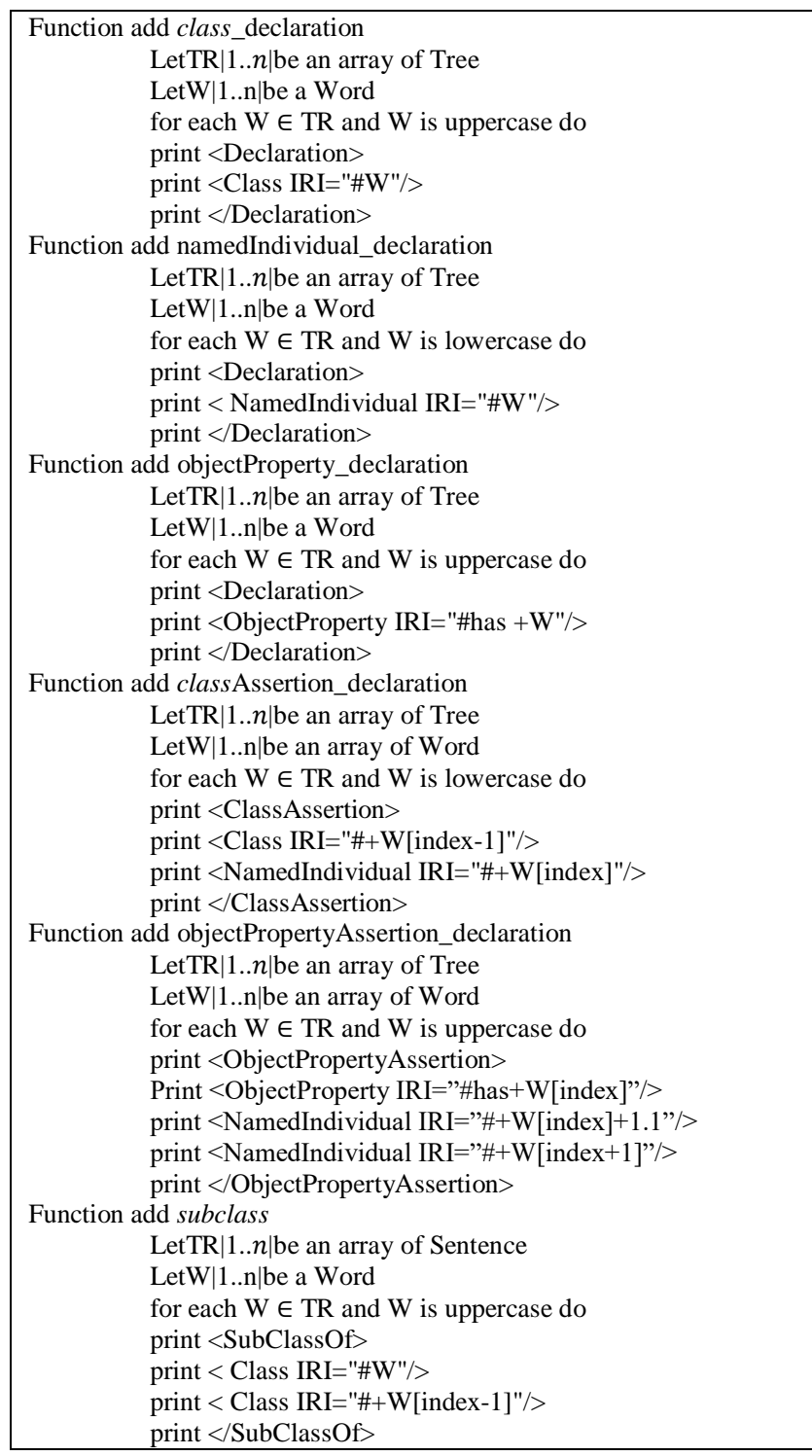

Gambar 4. Pseudocode konversi informasi ke dalam bentuk XML 
Hasil konversi informasi berbentuk hierarki ke dalam protégé ditunjukkan pada Gambar 5. Kotak dengan simbol lingkaran kuning menandakan class atau subclass kemudian kotak dengan simbol ketupat warna ungu merupakan instance dari suatu class. Pada contoh studi kasus ini, karnivora merupakan subclass dari hewan. Instance dari karnivora adalah katak, kucing dan buaya.

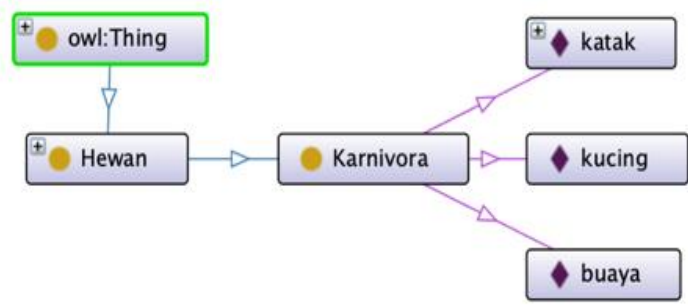

Gambar 5. Hasil Konversi kalimat berbentuk hierarki ke dalam Protégé

Kemudian untuk hasil konversi kalimat berbentuk nonhierarki ke dalam protégé ditunjukkan pada Gambar 6 . Terdapat beberapa class yang bernama S, Sub, Pre, Ket, dan Fprep. Class S merupakan representasi dari kalimat, class Sub merupakan representasi dari subjek, class Pre merupakan representasi dari predikat dan class Ket merupakan representasi dari keterangan. Class Fprep merupakan representasi dari frasa preposisi yang berkaitan dengan class keterangan. Class $\mathrm{S}$ memiliki relasi dengan Class Sub, Pre, dan Ket. Sedangkan class Ket memiliki relasi dengan class Fprep. Class S memiliki contoh instance yang diberi nama s1. s1 merepresentasikan kalimat ke 1. Kalimat kedua dan seterusnya dilabeli dengan s2, s3, s4 dan seterusnya. Class Sub, Pre, dan Ket memiliki instance berupa sub1.1, pre1.1, dan ket1.1. Penomoran yang diberikan pada setiap instance pada Sub, Pre dan Ket merujuk pada letak kalimat dan jumlah komponen tersebut dalam 1 kalimat. Misalkan Fprep1.1 adalah frasa preposisi pada kalimat pertama dan frasa preposisi yang pertama pada kalimat tersebut. Jika ada 2 frasa preposisi pada kalimat maka frasa preposisi selanjutnya akan dilabeli fprep1.2. Aturan tersebut juga berlaku pada instance dari class Sub dan Pre.

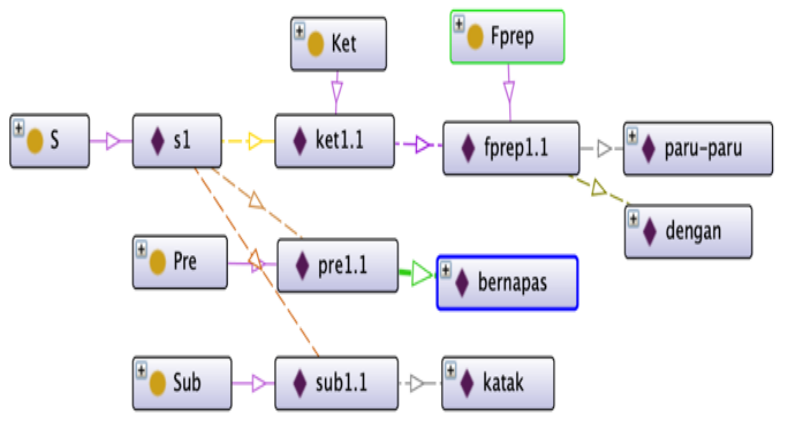

Gambar 6. Hasil konversi parse tree ke dalam Protege

Jika ontologi taksonomi dan ontologi kalimat dikombinasikan maka akan terlihat relasi informasi yang ada pada kedua ontologi tersebut, seperti yang ditunjukkan pada Gambar 7. Berdasarkan informasi pada
Gambar 7 diketahui bahwa katak adalah hewan karnivora yang bernapas dengan paru-paru. Informasi tersebut dapat semakin meluas dan mendalam seiring dengan penambahan informasi yang beralasi dengan informasi yang telah ada. Penggabungan informasi ini juga membuktikan bahwa model ontologi yang digunakan pada penelitian dapat digabungkan dengan informasi baru yang saling berkaitan (reusable).

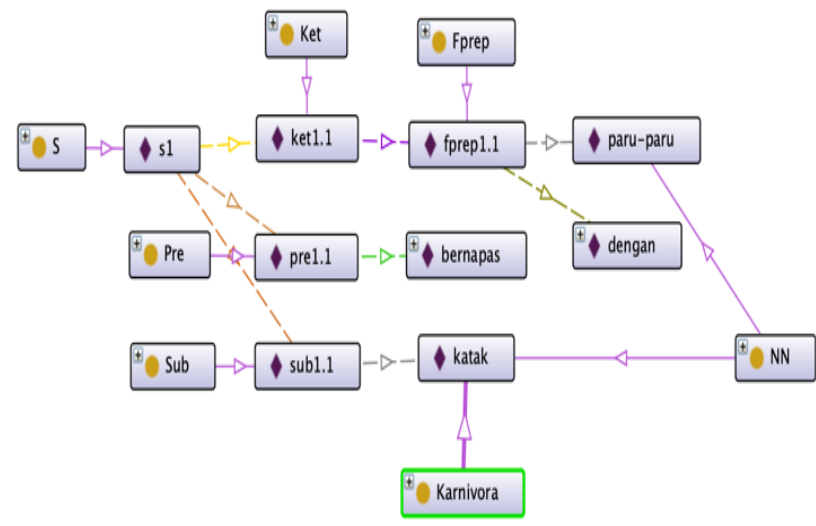

Gambar 7. Kombinasi ontologi taksonomi dan ontologi kalimat

\section{E. Pengambilan Informasi dari Protégé}

Pengambilan informasi dari Protégé dilakukan menggunakan kueri SPARQL. Kueri SPARQL akan menghasilkan triplet informasi. Informasi berbentuk triplet yang dihasilkan oleh SPARQL kemudian akan diubah menjadi rangkaian kalimat kembali agar lebih mudah dipahami oleh pengguna. Proses konversi informasi menjadi rangkaian kalimat yang utuh dilakukan dengan algoritma khusus yang telah dirancang oleh peneliti. Contoh kueri dan hasil yang digunakan untuk mengambil informasi dari ontologi taksonomi tentang katak ditunjukkan pada Gambar 8.

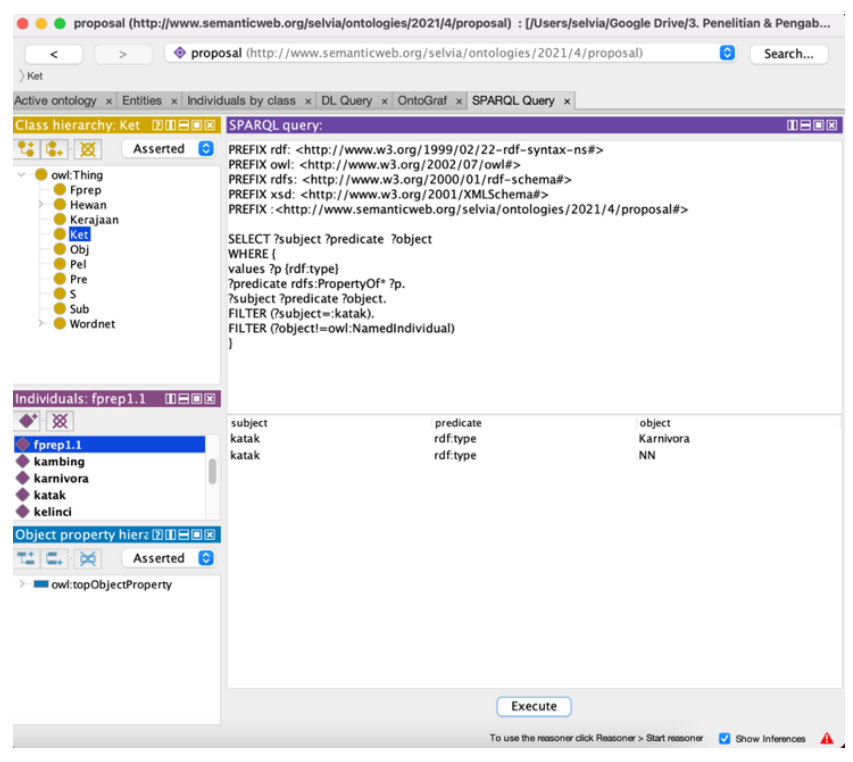

Gambar 8. Kueri SPARQL pada ontologi taksonomi 
Kueri pada ontologi taksonomi tentang katak menunjukkan bahwa katak merupakan noun dan bagian dari karnivora. Kemudian contoh kueri yang digunakan untuk mengambil informasi dari ontologi kalimat tentang katak ditunjukkan pada Gambar 9.

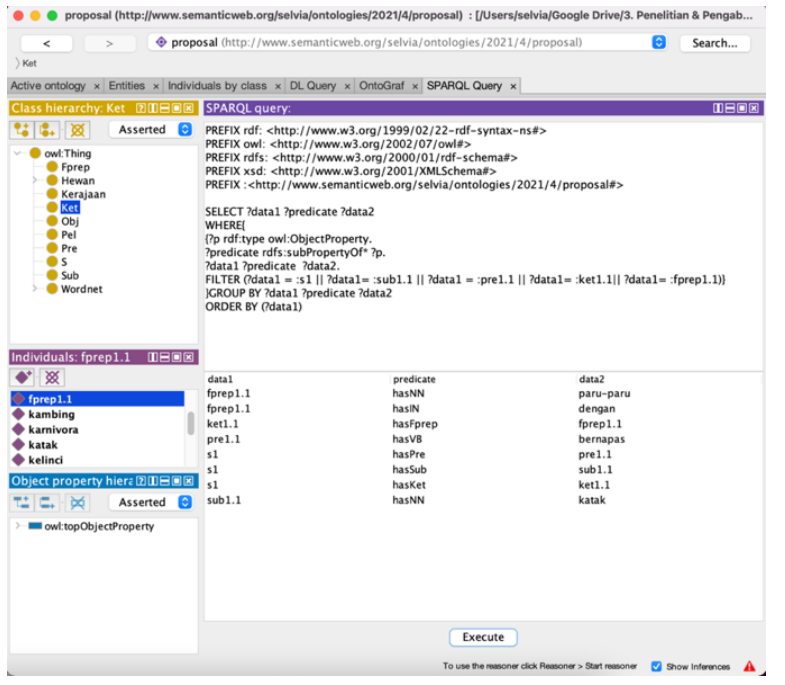

Gambar 9. Kueri SPARQL pada ontologi kalimat

\section{F. Konversi Hasil SPARQL}

Hasil kueri SPARQL ontologi kalimat pada Gambar 9 menunjukkan bahwa katak bernapas dengan paru-paru. Namun informasi pada setiap hasil kueri SPARQL tidak serta merta dapat dipahami dengan mudah. Oleh sebab itu perlu adanya konversi hasil kueri pada SPARQL yang berbentuk triplet menjadi satu kesatuan kalimat untuh. Proses konversi dilakukan dengan algoritma khusus yang dirancang untuk memahami susunan triplet dari hasil kueri untuk membentuk kalimat utuh. Pseudocode yang digunakan untuk mengubah hasil kueri SPARQL dari ontologi taksonomi dan ontologi kalimat menjadi kalimat utuh ditunjukkan pada Gambar 10.

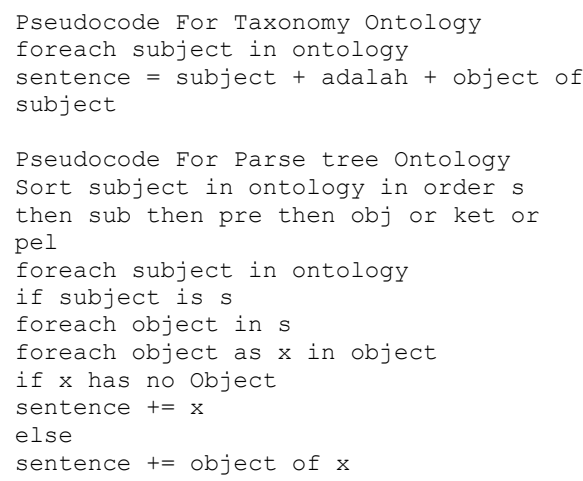

Gambar 10. Pseudocode konversi hasil kueri SPARQL menjadi Kalimat

\section{G. Evaluasi}

Proses evaluasi hasil representasi informasi berbentuk ontologi dilakukan dengan cara membandingkan hasil informasi yang dihasilkan metode yang diusulkan dengan informasi yang dijadikan ground truth. Ground truth adalah kumpulan informasi yang dibuat oleh ahli untuk dijadikan dasar perbandingan hasil. Informasi dikatakan benar jika poin perbahasan yang dihasilkan sama dengan informasi pada ground truth walaupun ada perbedaan struktur kalimat yang digunakan. Informasi dinyatakan salah jika informasi tersebut tidak tersedia dalam ground truth. Akurasi didapatkan dari perbandingan jumlah informasi benar yang dihasilkan oleh model yang diusulkan dibagi dengan keseluruhan informasi pada ground truth kemudian dikalikan $100 \%$.

Selain itu penelitian ini juga mengevaluasi efektifitas metode yang diusulkan. Evaluasi dilakukan dengan cara membandingkan model ontologi yang dihasilkan oleh penelitian ini dengan ontologi yang pernah ada. Fitur yang akan dijadikan perbandingan adalah penggunaan domain, penggunaan ahli, kemampuan reusable dan jumlah tahapan yang dimiliki. Jika ontologi yang dihasilkan bersifat domain oriented maka model ontologi tersebut tidak dapat digunakan oleh sembarang domain ontologi. Jika proses pembuatan ontologi menggunakan peran ahli maka konsistensi akan sulit dijaga karena terkadang ahli memiliki perbedaan pada proses representasi informasi. Kemampuan reusable juga penting untuk memastikan informasi dapat terus berkembang dan saling berelasi. Fitur yang terakhir adalah jumlah tahapan, semakin banyak jumlah tahapan proses pembangkitan ontologi maka akan semakin banyak waktu yang diperlukan untuk melakukan pembentukan ontologi.

\section{HASIL DAN PEMBAHASAN}

Penelitian ini menggunakan 2 materi pelajaran yang berbeda yaitu Ilmu Pengetahuan Alam (IPA) dan Ilmu Pengetahuan Sosial (IPS). Kedua studi kasus ini memiliki konsep informasi yang berbeda. Materi IPA identik dengan pengenalan struktur informasi berbentuk hierarki. Sedangkan materi IPS identik dengan sejarah, runtutan informasi maupun sebuah kejadian. Model ontologi yang diusulkan berhasil digunakan untuk menyimpan informasi dari kedua studi kasus tersebut. Contoh informasi dari materi IPA ditunjukkan pada Gambar 7. Sedangkan Contoh informasi dari materi IPS yang berhasil dikonversi ke dalam bentuk ontologi ditunjukkan pada Gambar 11.

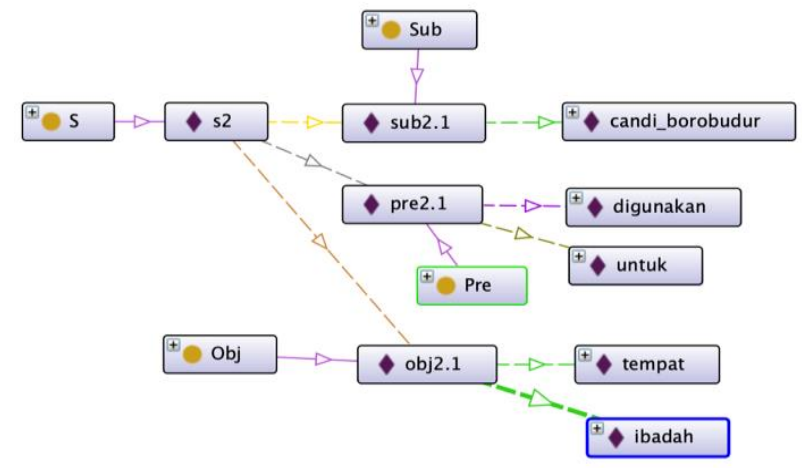

Gambar 11. Ontologi dari materi ilmu pengetahuan sosial 
Hasil uji coba ini membuktikan bahwa model yang diusulkan dapat digunakan untuk studi kasus yang berbeda. Pada dasarnya semua informasi dapat direpresentasikan dengan model ontologi yang diusulkan tanpa campur tangan ahli. Berbeda dengan model ontologi konvensional yang memerlukan peran ahli dalam proses penentuan dan pengelompokan komponen pembentuk ontologi. Gambar 12 merupakan gambar model ontologi konvensional yang dihasilkan dari informasi yang sama dengan Gambar 11. Kalimat yang digunakan untuk membentuk ontologi konvensional pada Gambar 12 adalah "Candi Borobudur digunakan untuk tempat ibadah". Ontologi yang dihasilkan pada Gambar 12 menunjukkan bahwa harus ada penambahan class yang berasal dari luar topik pembahasan hanya karena instance dari class tersebut diperlukan untuk melengkapi informasi yang akan disimpan. Contohnya adalah class fungsi tempat. Penamaan class juga menjadi masalah tersendiri. Belum tentu penamaan class ini benar menurut ahli yang lainnya. Pada model ontologi konvensional, diperlukan banyak sekali object property yang keseluruhan object property tersebut disesuaikan dengan kata kerja yang digunakan di setiap kalimat yang ingin direpresentasikan.

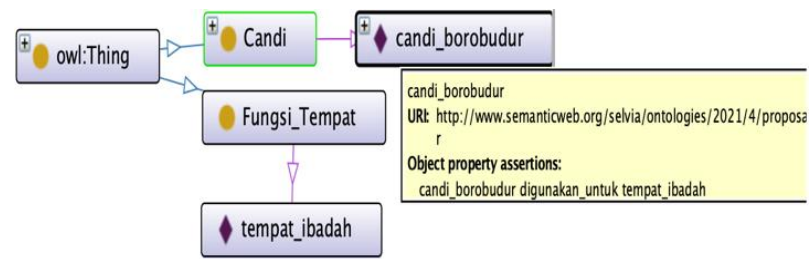

Gambar 13. Model ontologi konvensional

Berdasarkan hasil uji coba terhadap evaluasi tingkat keberhasilan penyimpanan informasi pada model ontologi yang diusulkan diketahui bahwa 100\% informasi yang ada pada ground truth dapat ditemukan pada ontologi yang dibangun. Hal tersebut membuktikan bahwa model representasi informasi yang diusulkan memiliki kehandalan yang baik untuk menyimpan informasi. Kesalahan penyimpanan informasi yang mungkin muncul adalah tidak ditemukannya objek karena objek dituliskan dengan kata ganti. Selain itu karena kalimat yang terlalu komplek sehingga model parse tree terkadang tidak sesuai aturan. Kesalahan kesalahan ini tidak terjadi karena pada proses awal sudah ada penyesuaian data agar tidak ada kesalahan seperti yang telah dijelaskan sebelumnya.

Selain terkait kapabilitas terhadap kemampuan menyimpan informasi, penelitian ini juga mengevaluasi efektivitas model yang diusulkan dibandingkan beberapa model yang dihasilkan oleh penelitian terkait metodologi pembangkitan ontologi yang pernah ada. Hasil dari perbandingan tersebut ditunjukkan pada Tabel 2 .

Tabel 2 menunjukkan bahwa penelitian yang diusulkan tidak bersifat domain oriented sehingga model yang terbentuk dapat digunakan untuk membentuk ontologi baru pada domain yang berbeda. Selain itu peran ahli juga dapat diminimalisir dalam proses pembuatan ontologi.
Model yang diusulkan dapat menghasilkan ontologi yang bersifat reusable. Selain itu tahapan yang dihasilkan juga tidak lebih dari 7 tahapan. Jika dibandingkan dengan penelitian terdahulu tentunya model yang diusulkan memiliki efektivitas dan efisiensi waktu yang lebih baik.

TABEL III

PERBANDINGAN EFEKTIVITAS MODEL ONTOLOGI DENGAN BEBERAPA PENELITIAN TERDAHULU

\begin{tabular}{|c|c|c|c|c|}
\hline \multirow[t]{2}{*}{ Penelitian } & \multicolumn{4}{|c|}{ Fitur Pembanding } \\
\hline & $\begin{array}{c}\text { Domain } \\
\text { Oriente } \\
\quad d\end{array}$ & $\begin{array}{c}\text { Ada } \\
\text { Peran } \\
\text { Ahli }\end{array}$ & $\begin{array}{l}\text { Reus- } \\
\text { able }\end{array}$ & $\begin{array}{c}\text { Jumla } \\
\text { h } \\
\text { Tahap } \\
\text {-an }>7\end{array}$ \\
\hline $\begin{array}{l}\text { SABiO: } \\
\text { Systematic } \\
\text { Approach for } \\
\text { Building } \\
\text { Ontologies [19] }\end{array}$ & Tidak & Ya & Ya & $\mathrm{Ya}$ \\
\hline $\begin{array}{l}\text { The Methodology } \\
\text { for Ontology } \\
\text { Development in } \\
\text { Lesson Plan } \\
\text { Domain [20] }\end{array}$ & Ya & $\mathrm{Ya}$ & $\begin{array}{l}\text { Tidak } \\
\text { dijelas- } \\
\text { kan }\end{array}$ & $\mathrm{Ya}$ \\
\hline $\begin{array}{l}\text { A simplified agile } \\
\text { methodology for } \\
\text { ontology } \\
\text { development[27] }\end{array}$ & Tidak & Ya & Ya & $\mathrm{Ya}$ \\
\hline $\begin{array}{l}\text { Expert2OWL: A } \\
\text { Methodology for } \\
\text { Pattern-Based } \\
\text { Ontology } \\
\text { Development } \\
\text { [28] }\end{array}$ & Ya & Ya & $\begin{array}{l}\text { Tidak } \\
\text { dijelas- } \\
\text { kan }\end{array}$ & $\mathrm{Ya}$ \\
\hline $\begin{array}{l}\text { A Semi- } \\
\text { automated } \\
\text { Ontology } \\
\text { Construction for } \\
\text { Legal Question } \\
\text { Answering [29] }\end{array}$ & Ya & Ya & $\mathrm{Ya}$ & $\mathrm{Ya}$ \\
\hline $\begin{array}{l}\text { Methodology for } \\
\text { Ontology Design } \\
\text { and Construction } \\
{[16]}\end{array}$ & Ya & Ya & $\mathrm{Ya}$ & $\mathrm{Ya}$ \\
\hline $\begin{array}{l}\text { Model yang } \\
\text { diusulkan }\end{array}$ & Tidak & Tidak & Ya & Tidak \\
\hline
\end{tabular}

\section{KESIMPULAN}

Ontologi merupakan salah satu metode yang dapat digunakan untuk merepresentasikan relasi informasi. Namun model ontologi yang ada saat ini masih bersifat domain spesifik. Proses pembuatan ontologi sangat bergantung pada ahli pada domain tersebut. Penelitian ini memperkenalkan model ontologi baru yang dapat meminimalisir peran ahli pada proses pembangkitan ontologi. Model ontologi baru yang diusulkan adalah kombinasi dari ontologi taksonomi dan ontologi kalimat. Informasi berbentuk hierarki akan direpresentasikan dalam bentuk ontologi taksonomi, sedangkan informasi non-hierarki akan direpresentasikan dalam bentuk ontologi kalimat. Berdasarkan uji coba yang telah dilakukan, terbukti bahwa model kombinasi ontologi yang 
diusulkan dapat menghasilkan ontologi yang tidak bersifat domain spesifik. Selain itu juga dapat mempermudah proses pembangkitan ontologi, dan mengurangi peran ahli dalam pembuatan ontologi.

\section{REFERENSI}

[1] S. Susanti, "Metode Mind Mapping Untuk Meningkatkan Hasil Belajar Ips Di Sekolah Dasar," J. Pendidik. Guru Sekol. Dasar, vol. 1, no. 1, pp. 25-37, 2016, doi: 10.17509/jpgsd.v1i1.9060.

[2] R. N. Hanifah, N. Y. Rustaman, and Saefudin, "Penggunaan Concept Map dan Mind Map untuk Mengembangkan Kemampuan Penalaran dan Penguasaan Konsep," Semin. Nas. Konserv. dan Pemanfaat. Sumber Daya Alam 2015, no. 1994, pp. 244-250, 2015

[3] D. Cahya et al., "Mind Mapping Model: Pengaruhnya Terhadap Hasil Belajar Tematik Siswa Sekolah Dasar," J. JPSD (Jurnal Pendidik. Sekol. Dasar), vol. 6, no. 1, pp. 1-8, 2019, doi: 10.12928/jpsd.v6i1.13435.

[4] S. P. Ramadhani, "PENINGKATAN HASIL BELAJAR IPA MELALUI MIND MAPPING DI TUMBUHAN DAN FUNGSINYA ( Penelitian Tindakan Kelas Pada Siswa Kelas IV , Kelurahan Manggarai , Kecamatan Tebet , Jakarta Selatan )," J. Ilm. Pendidik. Guru Sekol. Dasar, vol. 2, pp. 89-106, 2018.

[5] S. F. Kusuma, D. O. Siahaan, and C. Fatichah, "Automatic Question Generation in Education Domain Based on Ontology," in CENIM 2020 - Proceeding: International Conference on Computer Engineering, Network, and Intelligent Multimedia 2020, 2020, pp. 251-256, doi: 10.1109/CENIM51130.2020.9297991.

[6] E. Doynikova, A. Fedorchenko, and I. Kotenko, "Ontology of metrics for cyber security assessment," ACM Int. Conf. Proceeding Ser., 2019, doi: 10.1145/3339252.3341496.

[7] L. M. Schriml et al., "Human Disease Ontology 2018 update: Classification, content and workflow expansion," Nucleic Acids Res., vol. 47, no. D1, pp. D955-D962, 2019, doi: 10.1093/nar/gky1032.

[8] B. Diatta, A. Basse, and S. Ouya, "Bilingual ontology-based automatic question generation," in IEEE Global Engineering Education Conference, EDUCON, 2019, vol. April-2019, pp. 679-684, doi: 10.1109/EDUCON.2019.8725090.

[9] S. Ulfa, D. Barnabas, and C. Kurniawan, "Modelling the learner model based ontology in adaptive learning environment," vol. 1, no. 1, pp. 35-46, 2019.

[10] A. Karkar and J. Ji. M. Al, "An Educational Ontology-based MLearning System," iJIM, vol. 10, no. 4, pp. 48-56, 2016.

[11] S. Chimalakonda and K. V. Nori, "An ontology based modeling framework for design of educational technologies," arXiv, 2018.

[12] D. Baeva and D. Atanasova, "Ontology based resource for history education," TEM J., vol. 7, no. 4, pp. 782-786, 2018, doi: 10.18421/TEM74-13.

[13] I. Pistol, D. Trandabăț, and M. Răschip, "Medi-test: Generating tests from medical reference texts," Data, vol. 3, no. 4, pp. 1-12, 2018, doi: 10.3390/data3040070.

[14] J. Leo et al., "Ontology-Based Generation of Medical, Multi-term MCQs," Int. J. Artif. Intell. Educ., no. 29, pp. 145-188, 2019.
[15] R. Manna, P. Pakray, S. Banerjee, D. Das, and A. Gelbukh, "CookingQA: A question answering system based on cooking ontology," Lect. Notes Comput. Sci. (including Subser. Lect. Notes Artif. Intell. Lect. Notes Bioinformatics), vol. 10061 LNAI, pp. 67-78, 2017, doi: 10.1007/978-3-319-62434-1_6.

[16] M. Bravo, L. F. H. Reyes, and J. A. Reyes Ortiz, "Methodology for ontology design and construction," Contaduria y Adm., vol. 64 no. 4, pp. 1-24, 2019, doi: 10.22201/FCA.24488410E.2020.2368.

[17] D. Orozova and M. Todorova, "Ontology concept in courses on students," TEM J., vol. 7, no. 3, pp. 693-697, 2018, doi: 10.18421/TEM73-29.

[18] Y. S. Baskoro, H. Jayadianti, J. T. Informatika, F. T. Industri, K. Depok, and K. Sleman, "Ontologi Pada Domain Kriminalitas Kepolisian," TELEMATIKA, vol. 15, no. 01, pp. 13-29, 2018.

[19] R. De Almeida Falbo, "SABiO: Systematic approach for building ontologies," CEUR Workshop Proc., vol. 1301, 2014.

[20] A. Saad and S. Shaharin, "The Methodology for Ontology Development in Lesson Plan Domain," Int. J. Adv. Comput. Sci. Appl., vol. 7, no. 4, pp. 557-562, 2016, doi: 10.14569/ijacsa.2016.070472.

[21] T. Fruhwirth, W. Kastner, and L. Krammer, "A methodology for creating reusable ontologies," Proc. - 2018 IEEE Ind. CyberPhysical Syst. ICPS 2018, pp. 65-70, 2018, doi: 10.1109/ICPHYS.2018.8387639.

[22] E. M. Sibarani, M. Nadial, E. Panggabean, and S. Meryana, "A study of parsing process on natural language processing in bahasa Indonesia," in Proceedings - 16th IEEE International Conference on Computational Science and Engineering, CSE 2013, 2013, pp. 309-316, doi: 10.1109/CSE.2013.56.

[23] R. A. Sukamto and D. H. Widyantoro, "Penguraian Bahasa Indonesia dengan Menggunakan Pengurai Collins," Malindo, pp. $1-7,2009$.

[24] D. Anitia, Y. Munarko, and Y. Azhar, "Parsing Twitter Menggunakan Metode Left-Corner Parsing Dengan Memanfaatkan Pos Tagger," J. Repos., vol. 2, no. 7, p. 897, 2020, doi: 10.22219/repositor.v2i7.203.

[25] H. K. Wardana, I. Swanita, and B. W. Yohanes, "Sistem Pemeriksa Pola Kalimat Bahasa Indonesia berbasis Algoritme Left-Corner Parsing dengan Stemming," J. Nas. Tek. Elektro dan Teknol. Inf., vol. 8, no. 3, p. 211, 2019, doi 10.22146/jnteti.v8i3.515.

[26] M. R. Pratama, S. Kusumadewi, and T. Hidayat, "Penerapan Algoritma Lalr Parser Dan Context-Free Grammar untuk Struktur Kalimat Bahasa Indonesia," J. Teknol. Elektro, Univ. Mercu Buana, vol. 8, no. 1, pp. 1-8, 2017.

[27] S. Peroni, "A simplified agile methodology for ontology development," Lect. Notes Comput. Sci. (including Subser. Lect. Notes Artif. Intell. Lect. Notes Bioinformatics), pp. 1-12, 2017, doi: 10.1007/978-3-319-54627-8_5.

[28] K. Tahar, J. Xu, and H. Herre, "Expert2OWL: A methodology for pattern-based ontology development," Stud. Health Technol. Inform., vol. 243, pp. 165-169, 2017, doi: 10.3233/978-1-61499808-2-165.

[29] B. Fawei, J. Z. Pan, M. Kollingbaum, and A. Z. Wyner, "A Semiautomated Ontology Construction for Legal Question Answering," New Gener. Comput., vol. 37, no. 4, pp. 453-478, 2019, doi: 10.1007/s00354-019-00070-2. 